\title{
Utilisation of Plastifying and Fluxing Wastes of Plastics and Eggshell Powder in Manufacture of Eco-Friendly Floor Tiles
}

\author{
Ainomugisha Safiki", Twinemukama Joseph, Okello Thomas, Bazairwe Annette \\ Department of Lands and Architectural Studies, Faculty of Engineering, Kyambogo University, Kampala, Uganda \\ Email address: \\ sainomugisha@kyu.ac.ug (A. Safiki), josephtwine97@gmail.com (T. Joseph), tokello@kyu.ac.ug (O. Thomas), \\ annettebazairwe@gmail.com (B. Annette) \\ *Corresponding author
}

\section{To cite this article:}

Ainomugisha Safiki, Twinemukama Joseph, Okello Thomas, Bazairwe Annette. Utilisation of Plastifying and Fluxing Wastes of Plastics and Eggshell Powder in Manufacture of Eco-Friendly Floor Tiles. Journal of Civil, Construction and Environmental Engineering. Vol. 6, No. 1, 2021, pp. 13-20. doi: 10.11648/j.jccee.20210601.13

Received: January 30, 2021; Accepted: February 7, 2021; Published: February 27, 2021

\begin{abstract}
This study addresses the possibility of utilizing polypropylene plastics and eggshell wastes in the manufacture of eco-friendly floor tiles. Therefore, the research is part of the ongoing hunt for establishing sustainable alternatives for disposing off plastic and eggshell wastes around the globe. In this study polypropylene plastic wastes (PPW) are melted and used as a binder to eggshell powder (ESP) acting as a flux in the matrix. These are combined with fine aggregates. Three ternary mixes of PPW-ESP-Sand are made in the proportions of $50-0-50 \%, 55-10-35 \%$, and $60-20-20 \%$. Thirty six sample tiles of size $250 \mathrm{~mm}$ x $250 \mathrm{~mm}$ x $8 \mathrm{~mm}$ are cast. The physical properties of PPW, ESP, and sand are first established. Then, the effect of this PPW and ESP on the flexural strength, impact resistance, density, and water absorption of floor tiles made are investigated. Specifically, the bulk density of PPW, ESP and sand were 370,1280 , and $1700 \mathrm{Kg} / \mathrm{m}^{3}$ and specific gravities were $0.93,2.54$, and 2.64 respectively. Meanwhile, PPW-ESP-Sand mix of $60-20-20 \%$ had the lowest water absorption at $0.15 \%$ and also the lowest density of $1570 \mathrm{Kg} / \mathrm{m}^{3}$, and the highest modulus of rupture of $11.7 \mathrm{kN} / \mathrm{mm}^{2}$ compared to conventional ceramic tile at $3.9 \mathrm{KN} / \mathrm{mm}^{2}$. The tile manufactured from the mix of $60-20-20 \%$ also exhibited the highest resistance to impact damage although all samples had a coefficient of restitution $(\mathrm{e}=0)$. In conclusion, the study presents a novel finding of combining two wastes replacing conventional non-renewable resources of clay and feldspar to produce eco-friendly tiles. Therefore, implementing the findings will facilitate achieving United Nations sustainable development goals (SDG), i.e. goal 12 of responsible consumption and production.
\end{abstract}

Keywords: Eggshell Powder, Floor Tiles, Polypropylene Plastic Wastes, Sustainable

\section{Introduction}

The ever-increasing population has led to mainly two problems i.e. continuous high production of wastes and depletion of existing natural resources. World over, production of plastics has been on an increase, for example, from the period of 2015 to 2016 alone, their demand shot up from 320 to 330 million tons [1]. Therefore, this trend is likely to greatly affect the ecological systems and their life. For instance, once these plastics are disposed of in the environment they take a very long time because of their durability. Once disposed of in water bodies they tend to float on the surface due to their low density [2]. These plastics are generally categorized under natural plastics, semi-synthetic plastics, synthetic plastics, and thermoplastics [3]. Some of the dangers from plastic wastes are endangering aquatic life once thrown in water bodies [4], land pollution as a result of discharging toxic substances into the soil [5], air pollution experienced after burning of plastics which emits particulate emission and solid residue ash [6] among others.

Another environmental burden that has of recent seen a tremendous increase is eggshell waste i.e. in nations where the production of eggs for industrial use has increased. Food and Agricultural Organization (FAO) statistics show that globally egg production stands at 82.2 million tons as per the year 2019 [7]. Given that the eggshell approximates $11 \%$ of the egg's total weight $[8,9]$, therefore, this approximates to about 9.04 million tons of eggshell waste. 
As a part solution to these challenges, plastic wastes could be utilised for very high value products in the construction industry [10]. This is mechanical recycling as suggested by $[1,11]$. These plastics have demonstrated the potential of imparting strength in construction materials like creating plastic cement and serving as a binding agent $[10,12]$. In other studies, it has demonstrated potential of equally increasing strength properties of tiles [13]. This reduces the ecological and health problems associated with them [14].

Similarly, eggshell wastes could also be utilized in the construction industry by taking advantage of its properties like a high content of $\mathrm{CaCO}_{3}$. This serves as a partial ingredient for cement [15]. Additionally, ESP has the potential to serve as a filler by partially replacing fine aggregates [16].

Therefore, as part of the global concern to finding sustainable solutions specifically to address environmental concerns to do with waste generation, the construction industry has been proven as a potential sector. Additionally, it also facilitates sustainable utilization of the world's scarce resources.

Traditionally, tiles have been known to come from a ternary blend of clay-quartz-feldspar [14]. These natural raw materials have had challenges of being non-renewable and given the merits of waste utilization in the construction industry, these need to be taken advantage of. This eco-friendly propensity has triggered a number of studies to utilize these wastes for high economic and eco-friendly uses.

Several studies have been conducted to assess the possibility of incorporating industrial by-products and agricultural wastes in making ceramic tiles. Thus, several wastes, e.g. plastic wastes [17, 18], eggshell powder [19, 20], rice husk ash [21], fly ash [22-24], Tiles wastes [25], glass waste [26] and blast furnace slag [27] have shown potentiality in being utilized in making ceramic tiles.

In many of these studies, there is a paucity of literature that can be traced on using a ternary blend of plastic and eggshell wastes for making floor and wall tiles. However, this ternary blend of plastic waste and eggshell waste has shown good results where these two were used to make roof tiles [28]. Increasing these wastes led to an increase in water absorption and also continuous addition of these wastes led to a reduction on the density. Eggshell wastes were proven to act as a filler in the manufacture of roof tiles [28].

The plastic wastes play the role of either plasticity provider allowing proper compaction or strength, plus acting as a flux offering body densification. It also embeds the filler through its vitreous phase [29]. Meanwhile, the eggshell powder acts a filler together with the sand filler because of its quartzous nature [30]. Eggshells consist of Calcium carbonate to about $95 \%$, are resistant to water penetration and it is thus expected to increase on the strength of the tile sample. They have been successful used to partially replace fine aggregates, where $5 \%$ replacement of fine aggregates produced the best compressive strength [16].

Therefore, this study seeks to assess the possibility of utilizing plastic wastes and eggshell powder plastifying and fluxing behavior in making floor tiles [31].
The utilization of eggshell powder and plastic wastes aims at obtaining floor tiles that have low energy consumption during manufacture, outputting an eco-friendly building product, and promote zero-waste economy, cut on the demand for natural raw materials, and promoting 'waste to wealth' management practices.

\section{Materials and Experimental Procedures}

\subsection{Plastic Wastes}

Polypropylene (PP) plastic wastes (PPW) of the thermosetting plastic class was used in this study. These plastics have a density of about $0.94 \mathrm{~g} / \mathrm{cm}^{3}$, tensile strength 3200 - 5000Psi, water absorption $0.01 \%$, melting point between $160-166^{\circ} \mathrm{C}$, and softening point $140-150^{\circ} \mathrm{C}$ [32]. This PP was selected mainly because of its flexibility, widespread usage, and ease to soften, melt, shaped, or reshaped upon heating. It's able also to take on the shape of the mold upon cooling [4]. The PPW is to serve a plastifying function in the material mix, and binder effects. Plastics inform of polypropylene possess water-resistance properties, a relatively high bulk density that reduces the sample space.

The study samples were collected from one of the slum areas of Banda Kinawataka pits and drainage lines, Kampala city Uganda. They consisted mainly of basins, plates, cups jelly cans, food containers, and plastic screw top lids (Figure 1).

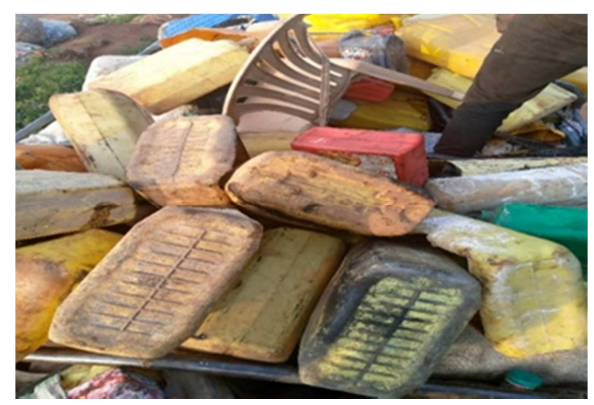

(a)

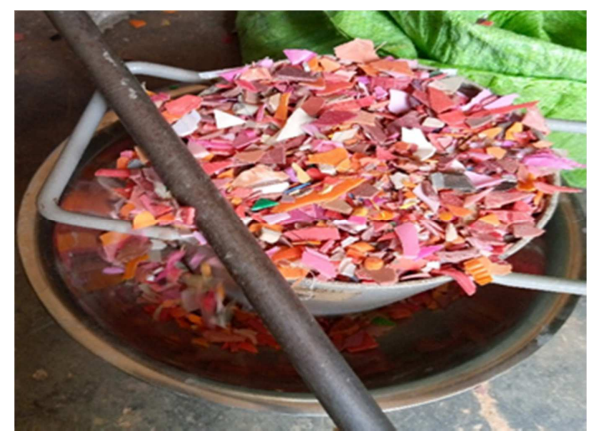

(b)

Figure 1. Polypropylene Plastic wastes a) after collection b) shredded samples.

The plastics were prepared by mechanical shredding in 
small pieces of about $700 \mathrm{~mm}$ (Figure 1b), thoroughly washed to remove glues plus all paper labels, dirt, and any possible remaining remnants. After washing, the sample was sun-dried and then tested for its physical properties (Table 1) before being melted for the production of floor tiles.

\subsection{Eggshell Wastes 2.3 Fine Aggregates}

Eggshell wastes (Figure 2) were collected from local bread makers "chapati" in Banda a Kampala city suburb in Uganda. They were prepared by washing them thoroughly in boiling water for about 5 - 10 minutes, soaking in water for 24 hours to facilitate easy removal of dirt and membranes.
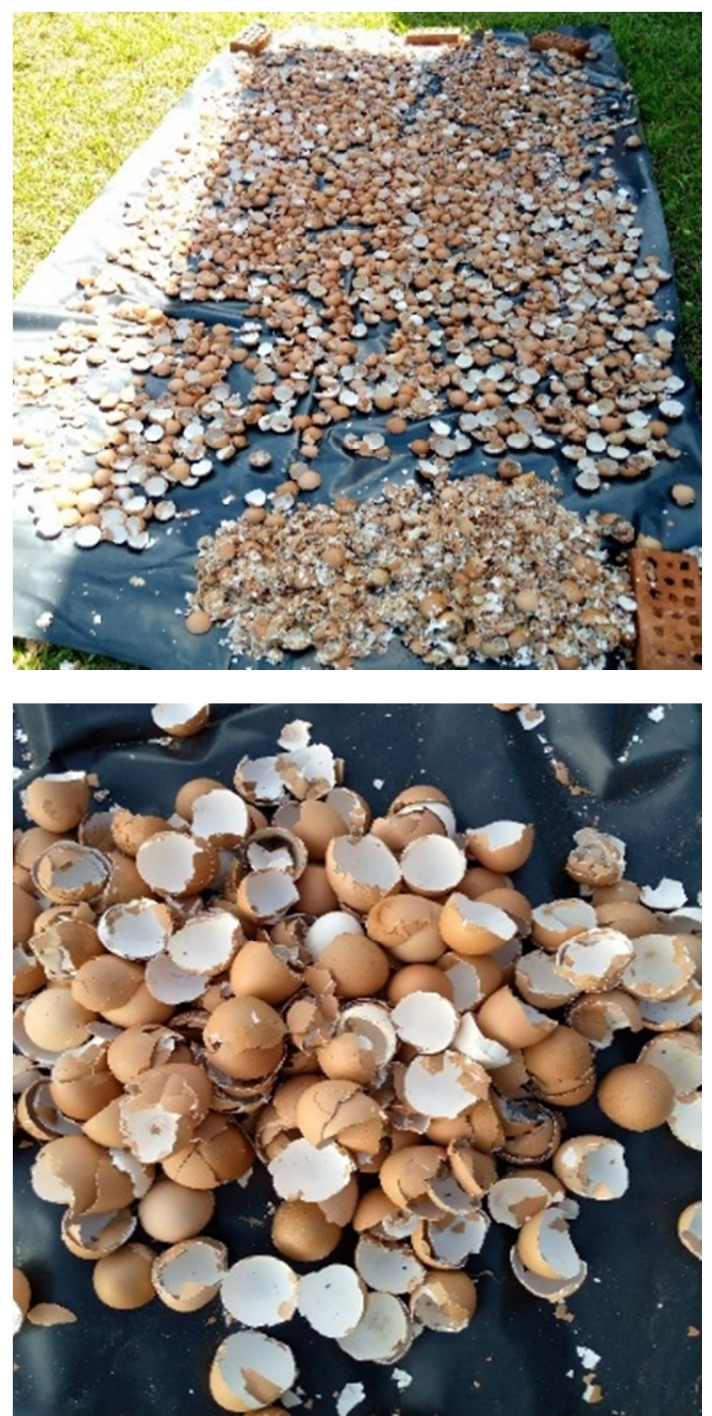

Figure 2. Eggshell wastes being sundried after cleaning.

After they were sun-dried for 4 days, pounded using a motor and pestle, and finally pulverised to produce eggshell powder using a milling machine. The powdered eggshell wastes were sieved through a $1.18 \mathrm{~mm}$ sieve so as to obtain the appropriate size of ESP to use as a filler in the ternary mixture. This was done following ASTM C136-06 procedure (sieve no. 16) [33].

\subsection{Fine Aggregates}

Fine aggregates of sand that satisfy the required standards and passing through 600 microns were used. It was sieved through $0.15-10 \mathrm{~mm}$ sieve. Sand was incorporated in the tile due to the quartz characteristics of $\mathrm{SiO}_{2}$. The sand is meant to provide the bulk of the tile. The test samples were first oven-dried at $105^{\circ} \mathrm{C}$. It was characterised by performing sieve analysis following BS 882:1992 [34] and results represented in Figure 3. The particle size distribution of fine aggregates (sand) showed that it was well graded as about $75 \%$ passed the 600 microns.

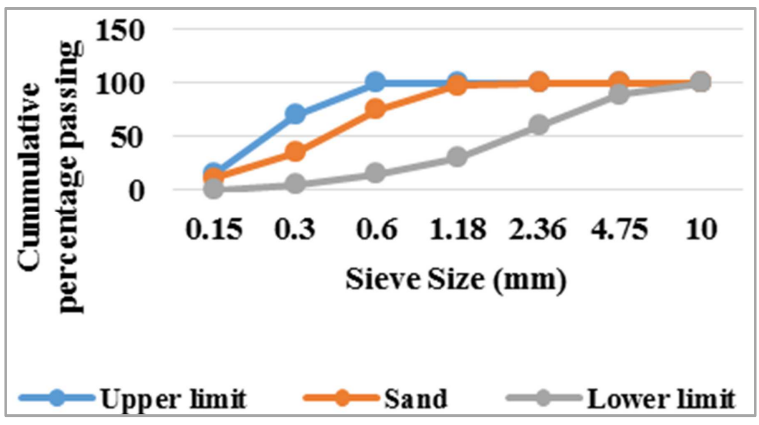

Figure 3. Sieve analysis curve for sand.

The specific gravity tests for the materials used were determined following procedures of ASTM D 854-00 standard test for the specific gravity of solids by water pycnometer [35] and IS-2720-Part-3-1980 [36]. Table 1 shows the bulk density and specific gravity of plastics, eggshell, and sand.

The bulk density as a measure to show the material effect on flow consistency and reflection of its packaging quantity was established following ASTM D1895B: standard test methods for apparent density and bulk factor [37].

Table 1. Physical properties of plastics, eggshells, and sand.

\begin{tabular}{ll}
\hline Physical properties of materials used & Test values \\
\hline Bulk density of plastics & $1700 \mathrm{Kg} / \mathrm{m}^{3}$ \\
Bulk density of sand & $1280 \mathrm{Kg} / \mathrm{m}^{3}$ \\
Bulk density of egg shell & $370 \mathrm{Kg} / \mathrm{m}^{3}$ \\
Specific gravity of sand & 2.64 \\
Specific gravity of eggshell & 2.54 \\
Specific gravity of plastics & 0.93 \\
\hline
\end{tabular}

The bulk densities of filler materials (sand and eggshell powder) are slightly different however satisfying the required density of a plasticity-provider (fines). Whereas that of plastics is found to be $370 \mathrm{Kg} / \mathrm{m}^{3}$ which is slightly lower than that recorded in the standard [32]. The bulk density is also lower than the bulk density of conventional materials that are normally used as a filler in construction.

The specific gravity of sand used falls in the range of 2.4-3.0 as specified by the ASTM C33 [38], while that of eggshell powder is found to be 2.54 which is within ASTM C33 range. However, other studies a slightly higher values are recorded at 3.37 like in [39]. Meanwhile, that of PPW was very close to the required standard of 0.9 as given by the 


\section{ASTM D792 [40].}

\subsection{Material Mix Matrix}

The PPW-ESP-Sand ratio matrix adopted was as indicated in Table 1. Three mixes were made while varying plastic wastes from $50-60 \%$ maintaining a $10-60 \%$ as suggested in [31]. For the eggshell powder it was varied between $0-20 \%$ also keeping it less than a $20 \%$ mix ratio as proposed by [31].

Table 2. Material mix ratios used.

\begin{tabular}{llll}
\hline Materials & Mix 1 (M1) & Mix 2 (M2) & Mix 3 (M3) \\
\hline Plastic Waste & $50 \%$ & $55 \%$ & $60 \%$ \\
Eggshell powder & $0 \%$ & $10 \%$ & $20 \%$ \\
Sand & $50 \%$ & $35 \%$ & $20 \%$ \\
\hline
\end{tabular}

\subsection{Tile Specimen Preparation}

For each mix after the dried plastics were measured in the proportion for each mix by weight, they were melted in a metallic reactor using gas as fuel to a melting at around $\left(150^{\circ} \mathrm{C}-170^{\circ} \mathrm{C}\right)$. After complete melting, well-sieved sand and eggshell powder were added little by little in the container while stirring. This mixture was stirred until a homogenous coloured mixture was attained. Thirty-six (36) sample tiles in total were manufactured of size $250 \mathrm{~mm} \times 250 \mathrm{~mm}$ x $8 \mathrm{~mm}$ (Figure 4).

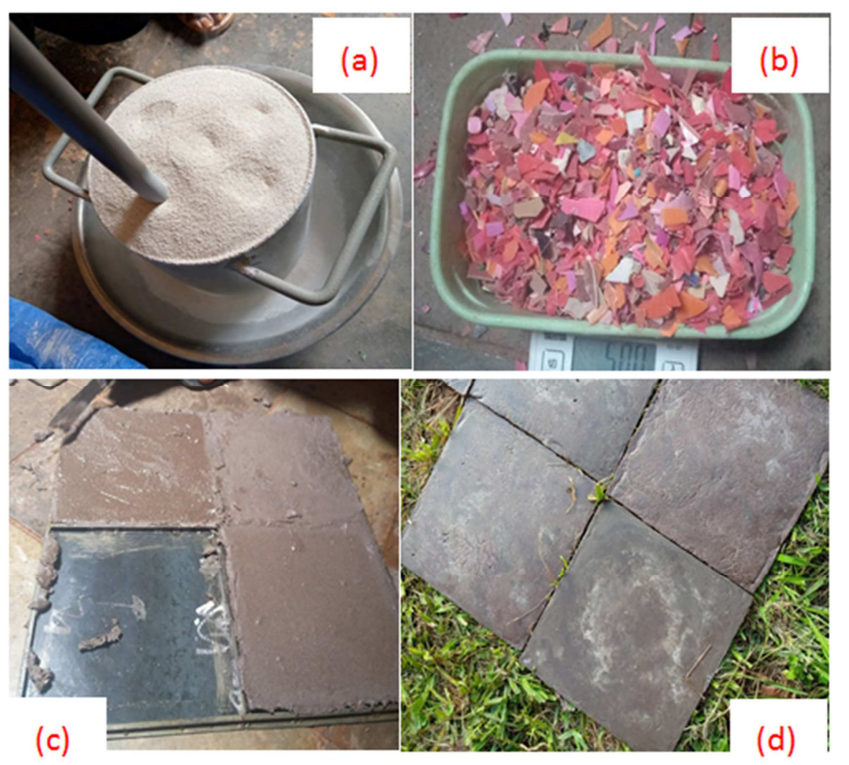

Figure 4. a) Eggshell powder; b) PPW; c) Tiles in mould; d) Manufactured floor tiles.

\subsection{Experimental Tests}

\subsubsection{Water Absorption}

To establish the capacity of the manufactured tile in relation to water absorption, the porosity of the tiles made was determined. This is necessary also because it helps to establish performance characteristics and is also used as a criterion for classifying ceramic tiles in ISO 13006: 2012 [41]. The water absorption test on the sample tiles was carried out according to ASTM C 373 standard test methods [42] for determining water absorption and BS EN ISO 10545-3: 1997 [43].

\subsubsection{Density of Sample Tiles}

This is the mass of the material per unit of its volume. It is an important factor the influences all strength properties of the tiles made. The density of the tiles made was computed, its weight measure accurately, and then its volume was computed from its measured dimension. The average density for each mixing ratio was then determined.

\subsubsection{Flexural Strength}

The bending strength of the tiles manufactured was determined on at least three samples of tiles for each sample mix and an average was obtained. This test was conducted in accordance with ASTM C 1505-01 [44] standard test method for determining of bend strength of tile using a three-point loading (Figure 5).

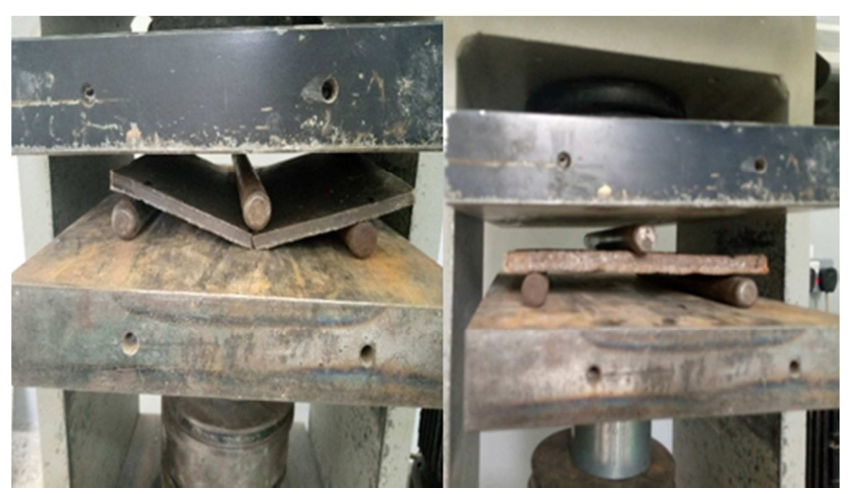

Figure 5. Performing flexural strength test using UTM.

\subsubsection{Impact Resistance}

Since building floors where tiles are used are more prone to impacts than walls, largely from falling object loads and point load characteristics experienced from footwear, impact resistance was established [45]. The measure of impact resistance helps to prove the durability of the tiles made under such circumstances. The impact resistance test was conducted following the American standard ASTM C648-84 [46] by measuring what is known as the restitution coefficient (e).

\section{Results and Discussion}

This section presents results and their discussion to give insight of the research in terms of engineering properties of plastic floor tiles. Tests include mechanical properties of flexural strength and impact resistance of sample tiles. Other investigations on the manufactured floor tile include density and water absorption following procedures given in the above section.

\subsection{Physical Properties of Floor Tiles Made}

\subsubsection{Water Absorption}

To determine the rate of permeability of the tile samples after 24 hours, water absorption was done on three (3) mix ratios, tile samples size $250 \times 250 \times 8 \mathrm{~mm}$ by soaking them in 
water. Once tiles absorb high water values it's likely to lead to cracking once they are put in areas prone to rainfall and freezing [47].

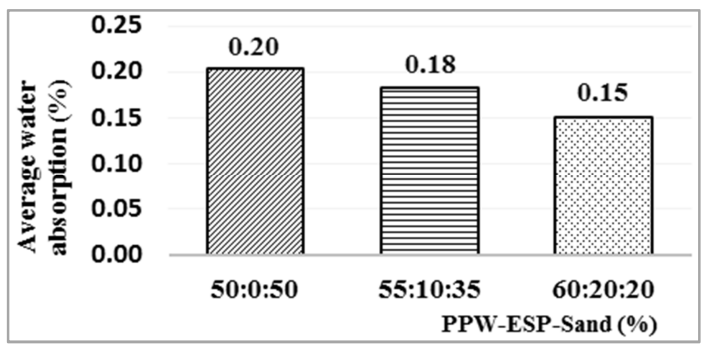

Figure 6. Water absorption of tiles made in PPW-ESP-Sand matrix.

Reduced water absorption was studied in relation to the addition of PPW and ESP. The water absorption rate reduced with the addition of the two wastes from $0.2 \%$ to $0.15 \%$.
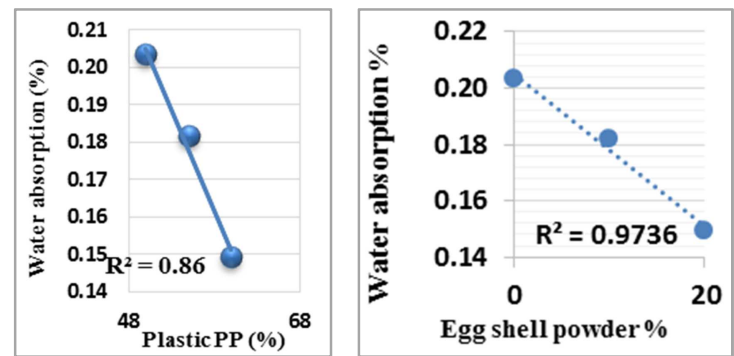

Figure 7. Statistical relationship of water absorption of tiles with PP and ESP.

As depicted in Figure 6 addition of PPW and ESP reduced on the permeability of floor tiles manufactured by $5 \%$ from $0.20 \%$ to $0.15 \%$. This is in agreement with studies who also found out that the water absorption of tiles made with plastics reduced from $3.8 \%$ to $1.01 \%$ [48]. Addition of plastic wastes to sawdust led to tiles of no water absorbed after 24 hours of immersion [49]. The reduction in permeability of tiles manufactured could be attributed to the addition of high water-resistant materials of PPW [19]. The results of the manufactured tiles using plastics and eggshell wastes with natural sand conformed to the minimum requirements of ASTM test method C373 [42] on water absorption for ceramic tiles. The standard requires an average water absorption of less than $0.5 \%$ for flooring. Additionally, the reduction in permeability with an increase in ESP could be attributed to ESP acting as a filler and limiting any water seepages through tiny voids created by sand particles.
There is a negative strong relationship (Figure 7) between eggshell powder and polypropylene plastics addition and water absorption of the tile samples up to $97.4 \%$ and $86 \%$. This strong relationship is an indicator that this permeability reduction is mainly attributed to an increase in plastics and eggshell powder than any other factors.

\subsubsection{Density of Manufactured Tiles}

The density of tiles manufactured first increased by $8 \%$ with a reduction of sand and increase in PPW and ESP. Then this fell by $14.3 \%$ with continuous addition of the same. Tiles made from in matrix of PPW-ESP-Sand $55-10-35 \%$ had the highest density at $1,832 \mathrm{~kg} / \mathrm{m}^{3}$ (Figure 8 ).

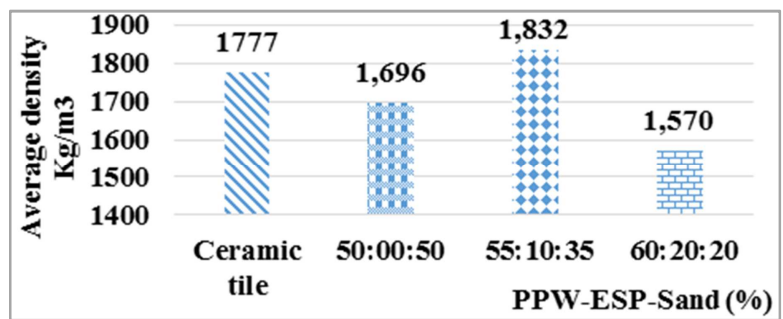

Figure 8. The average density of PPW-ESP-Sand manufactured and ceramic tiles.

A similar trend of results where the addition of plastics increased density and later reducing was obtained by [50]. However, this trend is generally attributed to the fact that when ESP was first introduced due to its high bulk density as a filler could have led to an increase in density of tiles made. However, when sand a high bulk density material of sand was continuously replaced by ESP, it led to a reduction in density by $14.3 \%$. Therefore, there was a weight loss when the percentage of ESP increased and sand reduced [51].

\subsection{Mechanical Properties of Floor Tiles Made}

\subsubsection{Flexural Strength}

The flexural strength or bend strength was studied as a measure of the highest stress experienced within the material at the moment of yielding [28]. The test was performed on at least three samples of tiles. This test was done according to ASTM C 1505-01 [44] standard test method for determining of bend strength of tile by three-point loading. The values of breaking strength and flexural strength were represented in Table 3 below.

Table 3. The flexural strength of the manufactured floor tiles.

\begin{tabular}{llll}
\hline PPW-ESP-Sand (\%) & Average Maximum breaking load (kN) & Breaking strength (N) & Average flexural strength (N/mm ${ }^{2}$ ) \\
\hline $50-0-50$ & 0.667 & 400 & 9.4 \\
$55-10-40$ & 0.800 & 480 & 11.3 \\
$60-20-20$ & 0.833 & 500 & 11.7 \\
Conventional ceramic tile) & 0.250 & 167 & 3.9 \\
\hline
\end{tabular}

It was observed that the flexural strength and breaking strength of the tile samples increased with an increase in PPW and ESP. The modulus of rupture improved by $25 \%$ when PPW and ESP were increased from $50-60 \%$ and $0-20 \%$ respectively (Table 3). These findings confirm with those of the previous researches where on the addition of more plastics led to an increase in flexural strength, like [48]. The strength improvement could be attributed to the stiffness properties of 
polypropylene and this makes the floor tiles best suitable in high stress areas [49]. There is generally an increase in bond strength provided by plastics which contributed to the increase in this bending load. This improvement is seen higher i.e. $20 \%$ when ESP was first introduced at $10 \%$. The subsequent addition of $20 \%$ ESP slightly increased the flexural strength by only $4.2 \%$. Generally, the improvement in bend strength in relation to ESP addition is attributed to it acting as a filler and facilitating for more stiffness within the tile body [16]. The reduction in subsequent strength improvement rate could be because as more ESP replaced a much stiffer sand, the mix moved towards the optimum of $20 \%$ as obtained by [31].

The modulus of rupture for all the tiles made in the PPW-ESP-Sand matrix was way above the traditional convention ceramic tile by at least $58 \%$.

However, the breaking strength and modulus of rupture of tiles made were below the minimum values as set ISO of 800 $\mathrm{N}$ and $18 \mathrm{MPa}$ respectively (ISO 13006, 2012) [41].

\subsubsection{Impact resistance}

The impact damage was studied to establish the likely damage on the manufactured tiles as a result of falling objects and point-load sources like footwear, like stiletto heels plus hobnailed boots. To investigate this property, and impact resistance test was conducted using a spherical steel ball weighing 350 grams was dropped from a height of $1 \mathrm{~m}$ from the tiles. The test was conducted on both the PPW-ESP-Sand manufacture tiles and onto the conventional ceramic tile.

This resistance to impact damage was assessed basing on two parameters i.e. coefficient of restitution, e and visual examination after impact. The impact damage by visual observation is as shown in Figure 9.

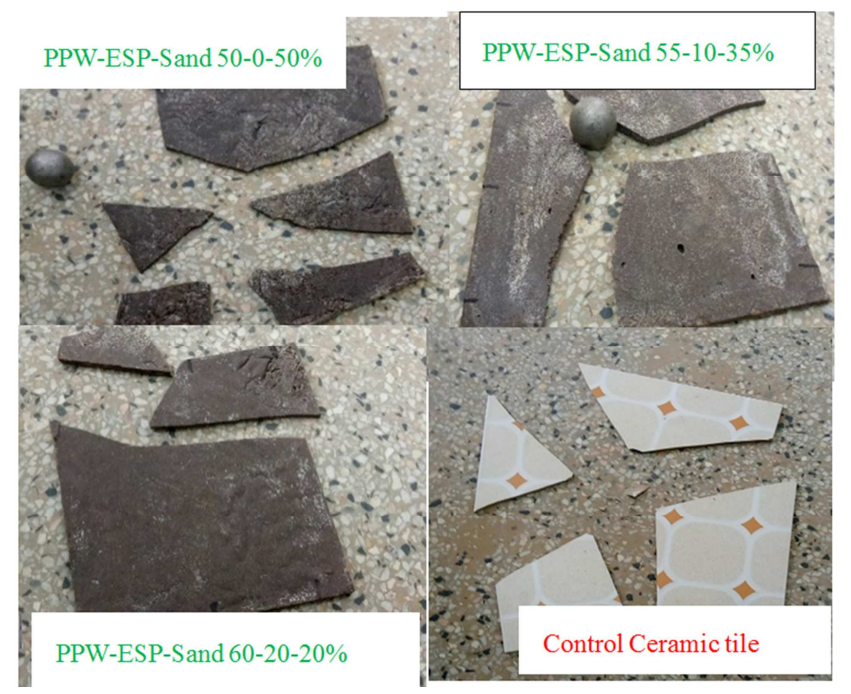

Figure 9. Visual observation of impact resistance test.

As a measure of good performance during service of the tiles made it was discovered that the damage reduced with an increase in PPW and ESP proportions in the tiles. The tile matrix of PPW-ESP-Sand $60-20-20 \%$ has the lowest observable shuttering damage by the dropped steel ball. Therefore, the $60-20-20 \%$ matrix under service is expected to offer some slight resistance under the impact. This could be attributed to the addition of more PPW that is said to have reduced the tile brittleness. Meanwhile, dropping the spherical steel ball onto ceramic tiles resulted in complete shuttering into smaller pieces of the tile body (Figure 9). This implied that conventional ceramic tiles are also brittle.

For the coefficient of restitution (e), it was obtained as zero since for all tiles the still ball did not rebound to a measurable height after the first impact. This implies there was almost no elastic shock and the ball almost became embedded within the tile. Almost all the energy possessed by the ball before dropping was utilized in modifying the tile body, friction, and the steel ball [53].

\section{Conclusions}

The findings demonstrate that tiles seem to be a possible avenue to solve the environmental challenges paused the plastics and eggshell wastes. This would reduce the pressure on the environment looking for landfills, additionally replace non-renewable natural resources of clay, feldspar and partially replacing sand.

A combination of PPW-ESP-Sand in proportions of $60-20-20 \%$ could produce tiles with better flexural strength, impact resistance, low permeability, lower impact damage, and low density.

This work has demonstrated a novel study with the tile matrix studied of PPW-ESP-Sand showing better results than plastics or eggshell only utilisation in making floor tiles as seen in previous studies.

The conventional matrix of clay-feldspar-quartz which are natural non-renewable resources could be substituted with the readily available wastes in the environment by about $80 \%$.

Finally, this study demonstrates a very important finding in the search for sustainable solutions for our environment.

\section{References}

[1] Plastics Europe, Recycling and Energy Recovery, 2020. Retrieved on 02/02/2020: https://www.plasticseurope.org/en/focus-areas/circular-econo my/zero-plastics-landfill/recycling-and-energy-recovery.

[2] Hopewell, J., Dvorak, R., \& Kosior, E. (2009). Plastics recycling: challenges and opportunities. Philosophical Transactions of the Royal Society B: Biological Sciences, 364 (1526), 2115-2126. https://doi.org/10.1098/rstb.2008.0311.

[3] Kehinde, O., Omotosho, O. A., \& Ohijeagbon, I. O. (2019, December). The Effect of Varying Sand and Plastic Additives on The Mechanical Properties of Cement Matrix Tiles. In Journal of Physics: Conference Series (Vol. 1378, No. 2, p. 022077). IOP Publishing.

[4] Kehinde, O., Ramonu, O. J., Babaremu, K. O., \& Justin, L. D. (2020). Plastic wastes: environmental hazard and instrument for wealth creation in Nigeria. Heliyon, 6 (10), e05131. https://doi.org/10.1016/j.heliyon.2020.e05131.

[5] Arthur H., \& Sina E., (2009): Adhesives technology handbook, Second Edition, Norwich, NY: William Andrew Inc. 
[6] Hanafi, A. Plastic Pollution: Nigeria‘s Untapped=waste Wealth 'Fuels Environmental Disaster, Punch Newspapers, 2018, pp. 18-19 Available from:

https://punchng.com/plastic-pollution-nigerias-untapped-waste -wealth-fuels-environmental-disaster/.

[7] FAO, 2020. Food and Agriculture Organization of the United Nations: Statistics Division (FAOSTAT) Production: Livestock Primary: Eggs Primary.

[8] Meski, S., Ziani, S., Khireddine, H., Yataghane, F., \& Ferguene, N. (2011). Elaboration of the hydroxyapatite with different precursors and application for the retention of the lead. Water Science and Technology, 63 (10), 2087-2096. https://doi.org/10.2166/wst.2011.210.

[9] Oliveira, D. A., Benelli, P., \& Amante, E. R. (2013). A literature review on adding value to solid residues: egg shells. Journal of Cleaner Production, 46, 42-47. https://doi.org/10.1016/j.jclepro.2012.09.045.

[10] Kehinde, O., Omotosho, O. A., \& Ohijeagbon, I. O. (2019), December). Impact of Varying Laterite and Cowhorn Additives on the Mechanical Properties of Cement Matrix Plastic Tiles. In Journal of Physics: Conference Series (Vol. 1378, No. 2, p. 022078). IOP Publishing.

[11] Duru, R. U., Ikpeama, E. E., \& Ibekwe, J. A. (2020). Challenges and prospects of plastic waste management in Nigeria. Waste Disposal \& Sustainable Energy, 1-10.

[12] Jassim, A. K. (2017). Recycling of polyethylene waste to produce plastic cement. Procedia manufacturing, 8, 635-642 https://doi.org/10.1016/j.promfg.2017.02.081.

[13] Siddique, R., Khatib, J., \& Kaur, I. (2008). Use of recycled plastic in concrete: A review. Waste management, 28 (10), 1835-1852. https://doi.org/10.1016/j.wasman.2007.09.011.

[14] Hossain, S. S., \& Roy, P. K. (2020). Sustainable ceramics derived from solid wastes: A review. Journal of Asian Ceramic Societies, 8 (4), 984-1009.

https://doi.org/10.1080/21870764.2020.1815348.

[15] Quina, M. J., et al., Applications of industrial eggshell as a valuable anthropogenic resource. Resour Conserv Recy (2016), http://dx.doi.org/10.1016/j.resconrec.2016.09.027.

[16] Palacio, A. J. C., Furiscal, N. G., Abalos, K. M. L., Alferez, D. A. A., Bade, E. A., Carumba, J. J. C., et al., \& Santos, F. D. (2020). Study of Coconut Charcoal Powder and Egg Shell Powder as Partial Replacement to Fine Aggregates and Cement in Load Bearing Concrete Bricks. In Key Engineering Materials (Vol. 853, pp. 120-125). Trans Tech Publications Ltd.

[17] Mohan, V., \& Gayathri, S. Effective Utilization of Plastic Wastes in Tile Manufacturing: A Step towards Sustainability.

[18] Hardikar, A., Borhade, O., Wagholikar, S., Shivdeo, A., \& Bhikule, R. Comparative Analysis of Tiles Made from Recyclable LDPE Plastic Waste.

[19] Freire, M. N., \& Holanda, J. N. F. (2006). Characterization of avian eggshell waste aiming its use in a ceramic wall tile paste. Cerâmica, 52 (324), 240-244.

[20] Hamada, H. M., Tayeh, B. A., Al-Attar, A., Yahaya, F. M., Muthusamy, K., \& Humada, A. M. (2020). The present state of the use of eggshell powder in concrete: A review. Journal of Building Engineering, https://doi.org/10.1016/j.jobe.2020.101583.
[21] Sobrosa, F. Z., Stochero, N. P., Marangon, E., \& Tier, M. D. (2017). Development of refractory ceramics from residual silica derived from rice husk ash. Ceramics International, 43 (9), 7142-7146. https://doi.org/10.1016/j.ceramint.2017.02.147.

[22] Luo, Y., Ma, S., Zheng, S., Liu, C., Han, D., \& Wang, X. (2018). Mullite-based ceramic tiles produced solely from high-alumina fly ash: preparation and sintering mechanism. Journal of Alloys and Compounds, 732, 828-837. https://doi.org/10.1016/j.jallcom.2017.09.179.

[23] Ji, R., Zhang, Z., Yan, C., Zhu, M., \& Li, Z. (2016). Preparation of novel ceramic tiles with high $\mathrm{Al} 2 \mathrm{O} 3$ content derived from coal fly ash. Construction and Building Materials, 114, 888-895. https://doi.org/10.1016/j.conbuildmat.2016.04.014.

[24] Wang, H., Zhu, M., Sun, Y., Ji, R., Liu, L., \& Wang, X. (2017). Synthesis of a ceramic tile base based on high-alumina fly ash. Construction and Building Materials, 155, 930-938. https://doi.org/10.1016/j.conbuildmat.2017.07.049.

[25] Ke, S., Wang, Y., Pan, Z., Ning, C., \& Zheng, S. (2016). Recycling of polished tile waste as a main raw material in porcelain tiles. Journal of Cleaner Production, 115, 238-244. https://doi.org/10.1016/j.jclepro.2015.12.064.

[26] Silva, R. V., De Brito, J., Lye, C. Q., \& Dhir, R. K. (2017). The role of glass waste in the production of ceramic-based products and other applications: A review. Journal of Cleaner Production, $\quad 167, \quad 346-364$. https://doi.org/10.1016/j.jclepro.2017.08.185.

[27] Ozturk, Z. B., \& Gultekin, E. E. (2015). Preparation of ceramic wall tiling derived from blast furnace slag. Ceramics International, $\quad 41 \quad$ (9), 12020-12026. https://doi.org/10.1016/j.ceramint.2015.06.014.

[28] Santhoshkumar et al. (2020) Effects of Plastic and Egg Shell Waste Materials on the Physical and Strength Properties of Roof Tiles.

[29] Dondi, M., 2018. Feldspathic fluxes for ceramics: Sources, production trends and technological value. Resources, Conservation and Recycling 133, 191-205.

[30] Dondi, M., Raimondo, M., Zanelli, C., 2014. Clays and bodies for ceramic tiles: Reappraisal and technological classification. Applied Clay Science 96, 91-109.

[31] Fernanda Andreola, Luisa Barbieri, Isabella Lancellotti, Cristina Leonelli, Tiziano Manfredini Recycling of industrial wastes in ceramic manufacturing: State of art and glass case studied.

[32] Karthick J, Jeyanthi R, \& Petchiyammal M. (2014). Experimental Study on Usage of Egg Shell as Partial Replacement for Sand in Concrete. International Journal of Advanced ResearchIn Education Technology (IJARET), Volume 1, 7-10.

[33] Standard, A. S. T. M. C136-06, 2006," Standard Test Method for Sieve Analysis of Fine and Coarse Aggregates," ASTM International, West Conshohocken, PA.

[34] Standard, B. (1992). BS 882: 1992. Aggregates from Natural Sources for Concrete. BSI, United Kingdom.

[35] ASTM, D. 854-00. Standard Test for Specific Gravity of Soil Solids by Water Pycnometer. In American society of testing Materials. 
[36] IS-2720-(Part 3), 1980. Methods of Test for Soils. Determination of Specific Gravity. Bureau of Indian Standards Publications, New Delhi.

[37] ASTM, 1996. American Society for Testing and Materials Standards. D1895-96. Standard Test Methods for Apparent Density, Bulk Factor, and Pourability of Plastics Materials. ASTM, West Conshohocken, PA.

[38] Standard specification for concrete aggregates, ASTM C 33, American Society for Testing and Materials, ASTM specification, Philadelphia; 1999.

[39] Yerramala, A. (2015). Properties of concrete with eggshell powder as cement replacement. Indian Concrete Journal

[40] ASTM D792. (2002). Standard Test Methods for Density and Specific Gravity of Plastics by Displacement.

[41] ISO 13006 / 2012, Ceramic Tiles - Definitions, Classification, Characteristics and Marking, Annex K and L, International Organization for Standardization (ISO), Geneva, 2012, pp. 38 43.

[42] ASTM C373 - 88,. (1999). Standard Test Method for Water Absorption, Bulk Density, Apparent Porosity and Apparent Specific Gravity of Fired Whiteware Products (Reapproved 1999). ASTM.

[43] STANDARD, B. BS EN ISO 10545-3 (1997). Ceramic Tiles-Part, 3 .

[44] ASTM C1505-01 (2007) Standard Test Method for Determination of Breaking Strength of Ceramic Tiles by Three-Point Loading.

[45] Roy, H., \& Ralph, B. (1992). The impact resistance of ceramic tiles and flooring. Ceram Research.
[46] Standard test method for Breaking Strength of Ceramic Tile, ASTM C648-84.

[47] Rajeev, P., Sanjayan, J. G., \& Seenuth, S. S. (2016). Assessment of thermal cracking in concrete roof tiles. Materials \& Design, 107, 470-477. https://doi.org/10.1016/j.matdes.2016.06.072.

[48] Momin, A. A, Kadiranaikar R. B., Siddarooda, \& Nagaraj K. (2014). Plastic Floor Tiles.

[49] Temitope, A. K., Abayomi, O. O., Ruth, A. O., \& Adeola, A. P. (2015). A pilot recycling of plastic pure water sachets/bottles into composite floor tiles: a case study from selected dumping site in Ogbomoso. J Mater Sci Eng, 4 (6), 1-5.

[50] Semanda, J. (2018). The Effects of Plastic and Egg Shell Waste Materials on the Physical and Strength Properties of Floor Tiles (Doctoral dissertation, JKUAT-PAUSTI).

[51] Freire, M. N., Sousa, S. J. G., \& Holanda, J. N. F. (2008, February). Using eggshell waste in red wall tiles. In Proceedings of the Institution of Civil Engineers-Waste and Resource Management (Vol. 161, No. 1, pp. 23-27). Thomas Telford Ltd. https://doi.org/10.1680/warm.2008.161.1.23.

[52] Seghiri, M., Boutoutaou, D., Kriker, A., \& Hachani, M. I. (2017). The Possibility of Making a Composite Material from Waste Plastic. Energy Procedia, 119, 163-169. https://doi.org/10.1016/j.egypro.2017.07.065.

[53] Institut De promocio Ceramica (2014). Physico-chemical characteristics impact resistance. Accessed on: $\mathrm{http} / / / \mathrm{www} 3 . i p c . o r g . e s / \mathrm{dms} / \mathrm{pdfs} /$ Baldosas ceramicas caracte risticas_fisico-quimicas/Impact_resistance/4-4-1-D\%20DOC1 2\%20ing-DEF_vPDF.pdf. 